\title{
Association between delayed transthoracic echocardiography and in-hospital mortality in type $A$ acute aortic dissection-associated ST-segment elevated myocardial infarction
}

\author{
Bei Liü, Li-Dong Cai", Yi Wang \\ Department of Cardiology, Shanghai General Hospital, School of Medicine, Shanghai Jiao Tong University, Shanghai, China \\ Contributions: (I) Conception and design: B Liu, Y Wang; (II) Administrative support: Y Wang; (III) Provision of study materials or patients: Y Wang; \\ (IV) Collection and assembly of data: B Liu, LD Cai; (V) Data analysis and interpretation: B Liu, Y Wang; (VI) Manuscript writing: All authors; \\ (VII) Final approval of manuscript: All authors. \\ \#These authors contributed equally to this work. \\ Correspondence to: Yi Wang. Department of Cardiology, Shanghai General Hospital, School of Medicine, Shanghai Jiao Tong University, Shanghai, \\ China. Email: wangyi2016@sjtu.edu.cn.
}

\begin{abstract}
Background: This study evaluates the association between transthoracic echocardiography (TTE) timing and in-hospital mortality among individuals presenting with ST-segment elevated myocardial infarction (STEMI) complicating type A acute aortic dissection (TAAAD).

Methods: This cohort study obtained the data of previously published case reports from searches of PubMed (1990-2020), and adults with STEMI secondary to TAAAD were finally included. Delayed TTE (dTTE) exposure was defined as when the TTE test was made available after antithrombotic management for STEMI due to an initially missed diagnosis of TAAAD. The primary outcome of interest was in-hospital mortality, comparing individuals with dTTE and those with emergency TTE (eTTE). The odds ratio (OR) with $95 \%$ confidence interval (CI) were calculated to provide an estimate of association.

Results: A total of 109 individuals with a mean age of 56.7 [standard deviation (SD) 12.9] years, and of whom 75 were men $(68.8 \%)$ presenting with STEMI complicating TAAAD were included. Of all patients, $68(62.4 \%)$ had a dTTE test, which tended to be associated with increased in-hospital mortality after adjustment (OR, 2.320; 95\% CI, 0.743-7.248). The association between dTTE and in-hospital death was significant only among patients presenting with a high-risk examination (HRE) (OR, 11.196; 95\% CI, 1.32294.803) and with surgical therapy (OR, 5.375; 95\% CI, 1.080-26.700), and not among those presenting with negative HRE (OR, 0.150; 95\% CI, 0.016-1.397) and no surgical therapy (OR, 0.177; 95\% CI, 0.008-4.018). Conclusions: This study found an association between dTTE and increased in-hospital mortality in TAAAD-associated STEMI patients with surgical management. This association warrants further investigation.
\end{abstract}

Keywords: ST-segment elevated myocardial infarction (STEMI), type A acute aortic dissection (TAAAD), transthoracic echocardiography (TTE)

Submitted Dec 10, 2020. Accepted for publication Mar 18, 2021.

doi: $10.21037 /$ jtd-20-3470

View this article at: http://dx.doi.org/10.21037/jtd-20-3470

\section{Introduction}

As two common causes of acute fatal chest pain, ST-segment elevated myocardial infarction (STEMI) and type A acute aortic dissection (TAAAD) are poles apart regarding their therapeutic strategies. The antithrombotic therapy required in cases of the former is an absolute contraindication for the latter, and timely diagnosis and emergency therapy are vital for the successful management of both. However, the 
rare incidence of coronary malperfusion complicates 10 $15 \%$ of TAAAD cases, making both diagnosis and therapy intractable (1-6). The high mortality rate of $1-2 \%$ per hour after symptom onset renders immediate surgical treatment vital for TAAAD. However, its relative infrequency, coupled with its similar clinical presentation to acute coronary syndromes (ACS), can significantly delay hospital arrival and definitive diagnosis and treatment, potentially worsening the prognosis. Thus, distinguishing TAAAD from STEMI at the initial medical contact is of great clinical significance.

Transthoracic echocardiography (TTE) is safe, can be easily applied at the bedside, and is recommended as an appropriate first-line imaging technique for suspected acute aortic dissection (AAD) (7-9). Direct TTE signs can rapidly identify patients requiring advanced imaging despite low clinical probability, and in integrated bundles with $\mathrm{D}$-dimer, negative TTE is useful for ruling out AAD (10). While TTE can also benefit early diagnosis, medical management, and even prognosis of patients with STEMI (11), its use is limited before emergent coronary reperfusion therapy to avoid an increase in total ischemic time. Previous data reveals the proportion of patients eventually diagnosed with $\mathrm{AAD}$ who receive an initial emergency diagnosis and management plan for ACS can be as high as $80 \%$. For such a population, TTE timing might be instructive to inform clinical decisions and guide the use of antithrombotic medications and procedures. Thus, in the setting of STEMI complicating TAAAD, the association between TTE timing and prognosis is of considerable interest and is the subject of the present study.

We sought to understand the association between TTE timing and in-hospital death and hypothesized that delayed TTE (dTTE), defined as its availability after antithrombotic therapy as contraindicated management for TAAAD, increases the in-hospital mortality in this patient population.

We present the following article in accordance with the STROBE reporting checklist (available at http://dx.doi. org/10.21037/jtd-20-3470).

\section{Methods}

\section{Study design, population, and setting}

This retrospective cohort study included patients (aged $\geq 18$ years) with STEMI complicating TAAAD from previously published case reports. All observations recorded in reports ceased when patients were discharged from the hospital or died. Case reports were identified from the PubMed (1990-2020) database using the search terms "aortic dissection and acute myocardial infarction" and "acute aortic syndromes and acute myocardial infarction". Abstracts of the identified papers were reviewed for appropriateness, and the reference lists of articles were manually checked for additional papers. Cases were included if they appeared in published case reports in which patients had been clinically diagnosed with STEMI caused by TAAAD. Cases in which an electrocardiograph (ECG) showed the presence of ST depression $\geq 1 \mathrm{~mm}$ in six or more surface leads (inferolateral ST depression), coupled with ST-segment elevation in aVR and V1, were also included due to the possibility of left main coronary artery obstruction $(12,13)$.

The exclusion criteria were as follows: patients diagnosed with Stanford type B aortic syndrome, STEMI patients with a non-TAAAD cause, patients with non-ST segment elevation, percutaneous coronary intervention (PCI) induced iatrogenic aortic dissection (AD), patients with spontaneous coronary dissection, case reports with no clear ECG description, and in-hospital STEMI as a complication of surgery for AAD.The study was conducted following the Declaration of Helsinki (as revised in 2013) and approved by the Shanghai General Hospital ethics committee affiliated with Shanghai Jiaotong University (NO.: [2018] 24). Informed consent was not required as the data relating to included patients were from previously published case reports.

\section{Clinical data collection}

Two investigators independently screened all titles and abstracts to identify cases that met the inclusion criteria. When discordance occurred, cases were adjudicated after discussion, and disagreements were resolved by joint review. Inpatient data regarding baseline demographics, including age, sex, and medical history, pain features, physical examination findings, and imaging modalities parameters were extracted (as available) from individual papers.

\section{dTTE exposure and outcomes}

Patients who underwent TTE after antithrombotic therapy (antiplatelet aggregation and anticoagulation treatment) were initiated as part of a therapeutic plan for ACS, with a missed TAAAD diagnosis were defined as dTTE. If TTE was not performed during the management process, patients 


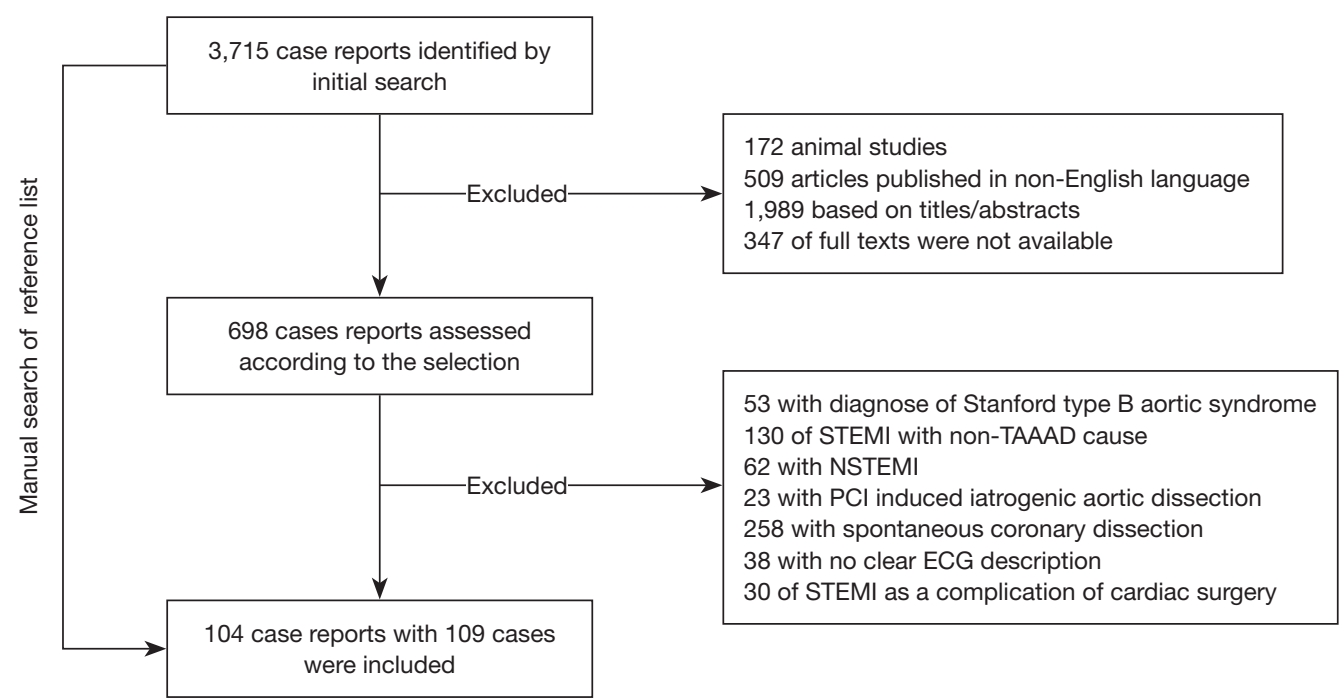

Figure 1 Flow diagram of case reports included in the final analysis. STEMI, ST-segment elevated myocardial infarction; TAAAD, type A acute aortic dissection; PCI, percutaneous coronary intervention; ECG, electrocardiograph.

were also classified as dTTE, and if emergency TTE (eTTE) was performed on admission before antithrombotic therapy for any reason, it was defined as no delay. The primary outcome of interest was in-hospital mortality, and cases with no reported in-hospital outcome were excluded.

\section{Statistical analysis}

IBM SPSS Statistic 25 was used to perform all statistical analyses. All normally distributed continuous variables were expressed as mean [standard deviation (SD)], and categorical variables were expressed as frequencies (\%). Univariate comparisons between groups were performed using the $\chi^{2}$ or Fisher's exact test for categorical data and the $t$-test for normally distributed continuous variables. In all cases, missing data were not defaulted to negative, and denominators reflect only cases reported. Univariate logistic regression and multivariate logistic regression models were used to examine whether dTTE and surgery had an independent effect on in-hospital death. In addition to demographic variables such as age, covariates associated with either dTTE or in-hospital mortality $(\mathrm{P}<0.05)$ were introduced into multivariate logistic regression. As dTTE was defined based on antithrombotic therapy, relevant variables such as CAG and aortography were rejected for multivariate analysis. Odds ratios (ORs) and hazard ratios with their corresponding $95 \%$ confidence intervals (CIs) were generated to provide an estimate of these associations, and a pre-specified subgroup analysis of dTTE and inhospital death in patients with high-risk examinations (HREs) and surgery was respectively performed. All P values were calculated using two-tailed statistical significance tests with a type I error rate of $5 \%$. Finally, as this was a retrospective analysis of the data from previously published cases, it does not apply to the sample size calculation.

\section{Results}

\section{Demographics}

The initial search identified 3,715 case reports (Figure 1). After excluding articles that were animal studies, not published in English, were not full texts, or were judged as irrelevant, the remaining 698 case reports were examined according to our defined selection criteria. Among these, 595 were excluded based on the exclusion criteria, and one case published in 1989 was manually found from the references list, leaving 104 reports with 109 cases eligible for final inclusion (see online Table S1). As shown in Table 1, 68.8\% of patients were male, and all patients' mean age was $56.7 \pm$ 12.9 years. On admission, the mean systolic blood pressure (BP) of patients was $100.4 \pm 34.2 \mathrm{mmHg}$, the mean diastolic $\mathrm{BP}$ was $59.9 \pm 21.4 \mathrm{mmHg}$, and the mean heart rate was $74.5 \pm 25.5 \mathrm{bpm}$. Patients with dTTE had lower levels of BP compared with patients with eTTE. The reported aortic dissection risk scores (ADRS) included ADRS $=0$ in $1.1 \%$ of the patients, $=1$ in $33.0 \%,=2$ in $61.7 \%$, and $=3$ in $4.3 \%$ each. 
Table 1 Baseline clinical characteristics and management

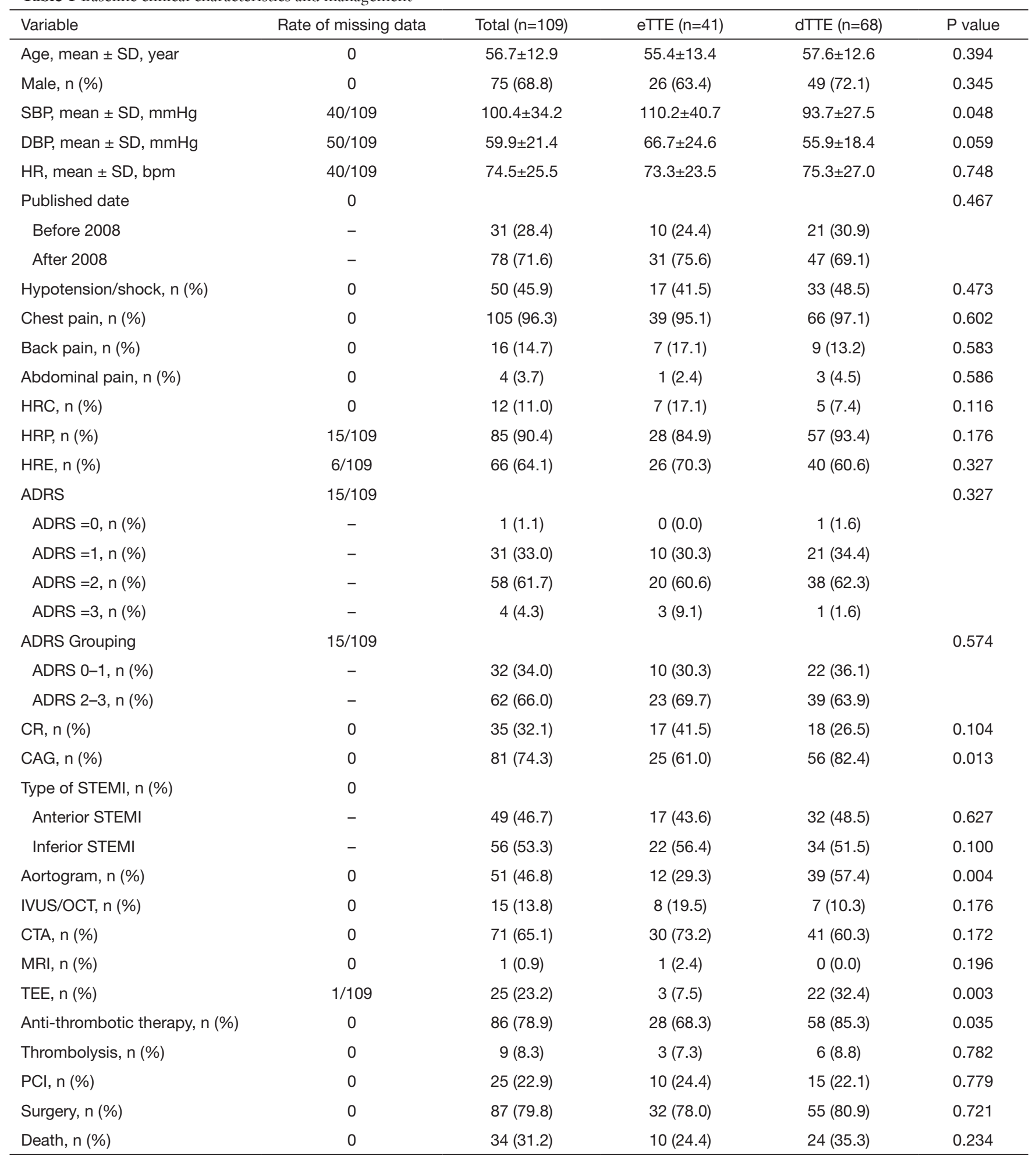

SD, standard deviation; TTE, transthoracic echocardiography; SBP, systolic blood pressure; DBP, diastolic blood pressure; HR, heart rate; ADRS, aortic dissection risk score; HRC, high-risk condition; HRP, high-risk pain; HRE, high-risk examination; CR, chest radiograph; CAG, coronary angiography; STEMI, ST-segment elevated myocardial infarction; IVUS, intravascular ultrasound; OCT, optical coherence tomography; CTA, computed tomography angiography; MRI, magnetic resonance imaging; TEE, transesophageal echocardiography; PCI, percutaneous coronary intervention. 
Data on the type of acute myocardial infarction (AMI) based on ECG were available in 105 patients, of which 49 (46.7\%) presented with anterior STEMI and 56 (53.3\%) with inferior STEMI. No differences in ADRS and myocardial infarction (MI) type between groups were observed. Finally, more patients in dTTE received antithrombotic therapy than those in the eTTE group ( $85.3 \%$ vs. $68.3 \%, \mathrm{P}=0.035)$.

\section{Imaging tests and TTE timing exposure}

Coronary angiography (CAG) was performed in 81 (74.3\%) patients, and of these, $15(13.8 \%)$ received intravascular imaging tests. In all patients, $71(65.1 \%)$ had CTA, and 25 (23.2\%) had transesophageal echocardiography (TEE). While most patients (90.8\%) received TTE at some point

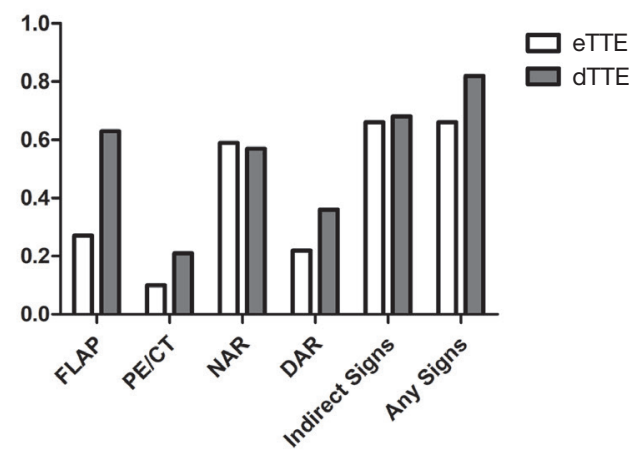

Figure 2 Differences of TTE signs between groups. The results were compared between groups based on TTE timing (before and after antithrombotic therapy). Direct signs include flap, penetrating aortic ulcer, and intramural hematoma. Indirect signs include new aortic regurgitation (NAR), dilated aortic root (DAR), and pericardial effusion/cardiac tamponade (PE/CT). eTTE, emergency transthoracic echocardiography; dTTE, delayed TTE. during their management, in more than half (62.4\%), this was delayed. In patients with dTTE, more had CAG, aortogram, and TEE compared with patients with eTTE. Interestingly, more direct TTE signs of TAAAD, such as an intimal flap, were reported in patients with the dTTE test than those with eTTE (Figure 2).

\section{Association between dTTE and outcomes}

Among all included cases, 34 (31.2\%) were in-hospital deaths. As shown in Table S2, patients with a positive HRE had a higher risk of in-hospital death than those with a negative HRE (78.12\% vs. $57.75 \%, \mathrm{P}=0.046)$, and patients with dTTE had a higher hazard for in-hospital mortality (OR, 1.691; 95\% CI, 0.709-4.033) at univariate analysis. At the multivariable regression analysis, dTTE tended to increase in-hospital death (OR, 2.320; 95\% CI, $0.743-$ 7.248) after being adjusted for age, surgery, TEE, and HRE (Table 2). In a further subgroup analysis, dTTE in patients with positive HRE (OR, 11.196; 95\% CI, 1.322-94.803) and patients receiving surgery (OR,5.375; 95\% CI, 1.08026.700) were significantly associated with higher in-hospital mortality respectively (Table 3).

\section{Remedial clues for suspected TAAAD during CAG}

A delay in diagnosing TAAAD may be unavoidable in patients presenting as STEMI with non-specific conditions/clinical manifestations or low ADRS (0-1). In these cases, TAAAD should be considered when catheter operation is difficult, characteristic angiographic abnormalities, and an inconsistency between angiographic imaging and clinical manifestations during the CAG procedure, and further imaging tests should be planned

Table 2 Association between delayed transthoracic echocardiography and in-hospital mortality

\begin{tabular}{|c|c|c|c|c|c|c|c|c|}
\hline \multirow{3}{*}{$\begin{array}{l}\text { Variable } \\
\text { dTTE }\end{array}$} & \multicolumn{4}{|c|}{ Univariable analysis } & \multicolumn{4}{|c|}{ Multivariable analysis ${ }^{*}$} \\
\hline & \multirow{2}{*}{$\frac{\mathrm{OR}}{1.691}$} & \multicolumn{2}{|c|}{$95 \% \mathrm{Cl}$} & \multirow{2}{*}{$\begin{array}{c}P \text { value } \\
0.236\end{array}$} & \multirow{2}{*}{$\frac{\mathrm{OR}}{2.320}$} & \multicolumn{2}{|c|}{$95 \% \mathrm{Cl}$} & \multirow{2}{*}{$\begin{array}{c}P \text { value } \\
0.148\end{array}$} \\
\hline & & 0.709 & 4.033 & & & 0.743 & 7.248 & \\
\hline Age & 1.016 & 0.984 & 1.049 & 0.342 & 0.995 & 0.952 & 1.039 & 0.805 \\
\hline Surgery & 0.071 & 0.023 & 0.221 & 0.000 & 0.044 & 0.010 & 0.189 & 0.000 \\
\hline TEE & 1.032 & 0.395 & 2.694 & 0.949 & 0.824 & 0.210 & 3.223 & 0.780 \\
\hline HRE & 2.613 & 0.999 & 6.834 & 0.050 & 4.357 & 1.196 & 15.875 & 0.026 \\
\hline
\end{tabular}

*, adjusted for age, surgery, TEE, HRE. dTTE, delayed transthoracic echocardiography after electrocardiograph; TEE, transesophageal echocardiography; HRE, high-risk examination. 
Table 3 Subgroup analysis of delayed transthoracic echocardiography on in-hospital mortality

\begin{tabular}{lll}
\hline Variables & OR & $95 \% \mathrm{Cl}$ \\
\hline Shock & & \\
Without shock & 1.398 & $0.269-7.273$ \\
With shock & 4.327 & $0.440-42.593$ \\
HRE & & \\
HRE $=0$ & 0.150 & $0.016-1.397$ \\
HRE $=1$ & 11.196 & $1.322-94.803$ \\
ADRS & & \\
ADRS =0-1 & 0.298 & $0.014-6.537$ \\
ADRS =2-3 & 4.741 & $0.863-26.030$ \\
Surgery & & $0.008-4.018$ \\
No surgery & 0.177 & $1.080-26.700$ \\
Surgery & 5.375 &
\end{tabular}

HRE, high-risk examination. ADRS, aortic dissection risk score.

(Figure 3).

\section{Discussion}

In this retrospective cohort study, dTTE tended to be associated with a higher risk-adjusted in-hospital mortality in STEMI, complicating TAAAD patients receiving surgical therapy. While establishing a causal link between TTE timing and patient outcomes was not the aim of this study, the observed association may assist physicians in management decisions (14).

\section{In-hospital mortality and delay in TAAAD diagnosis and therapy}

With the significant increase in surgical management employed to treat TAAAD over the past 20 years, the overall in-hospital mortality has decreased significantly from $31 \%$ to $22 \%$ (15), while in those managed medically, the rate has remained unchanged at $57 \%(16)$. The inhospital mortality in the present study was $31.2 \%$, which is slightly higher than that in the International Registry of Acute Aortic Dissection (IRAD). In those patients who managed surgically, the rate was similar to that seen in IRAD $(20.0 \%$ vs. $18 \%)$, but those receiving medical therapy without surgery had higher mortality than IRAD $(77.3 \%$ vs. $57.0 \%)$. As an independent predictor of in- hospital mortality, shock in the present cases was almost twice as high as in IRAD (44.4\% vs. $15.0 \%)(16,17)$. This may reflect the complication of coronary malperfusion. Also, previous studies have demonstrated patient outcomes can be compromised if therapeutic measures are delayed or misappropriated. In cases where symptoms are not specific, ECG with new Q wave or ST-segment changes has been documented to cause delays in diagnosis $(18,19)$ and contraindicated management, including antithrombotic therapy and even thrombolysis, in TAAAD. Other variables associated with a delayed diagnosis include female sex, the absence of typical historical features or HRE findings, including hypotension or pulse deficits, and initial visitation to nontertiary hospitals. These findings suggest the need for earlier detection and aggressive surgical treatment to provide a reasonable chance of survival to these patients with an otherwise dismal prognosis.

\section{Underused TTE in TAAAD screening}

TTE is a tool providing relevant bedside data and has a sensitivity of $78 \%$ to $100 \%$ with a specificity of $93-96 \%$ for TAAAD (20-22). The advantages of TTE, including its ready availability and ability to be performed quickly and at the bedside, make it the test of choice to be used in early screening for TAAAD. Combined with ADRS $\leq 1$, a negative TTE had a sensitivity of $93.8 \%$ and a failure rate of $1.9 \%$ for ruling out AAD. However, data from the IRAD showed TTE was used in only $25 \%$ of cases as an initial diagnostic study (16), indicating underuse of TTE in $\mathrm{AD}$ pre-inspection. In the present study, although $90.8 \%$ of cases underwent TTE during in-hospital management, only $37.6 \%$ did so immediately on admission before antithrombotic therapy. Of these, at least one suspicious sign of TAAAD was found in $65.9 \%$, including $11(26.8 \%)$ with flap, 4 (9.8\%) with pericardial effusion, 24 (58.5\%) with new aortic regurgitation, and $9(22.0 \%)$ with a dilated aortic root. In STEMI patients, routine TTE before reperfusion therapy is unnecessary in order to reduce the total ischemic time (12). However, eTTE is reasonable for a particular STEMI population with cardiac arrest, cardiogenic shock, hemodynamic instability or suspected mechanical complications, and an uncertain diagnosis. In this study, in patients with a high probability of $\mathrm{AAD}$, only one-third $(34.0 \%$ in shock and $37.0 \%$ in ADRS of $2-3)$ received eTTE, which was not in compliance with the recommendation of STEMI guidelines and indicated underuse of eTTE for appropriate indications. Equally 


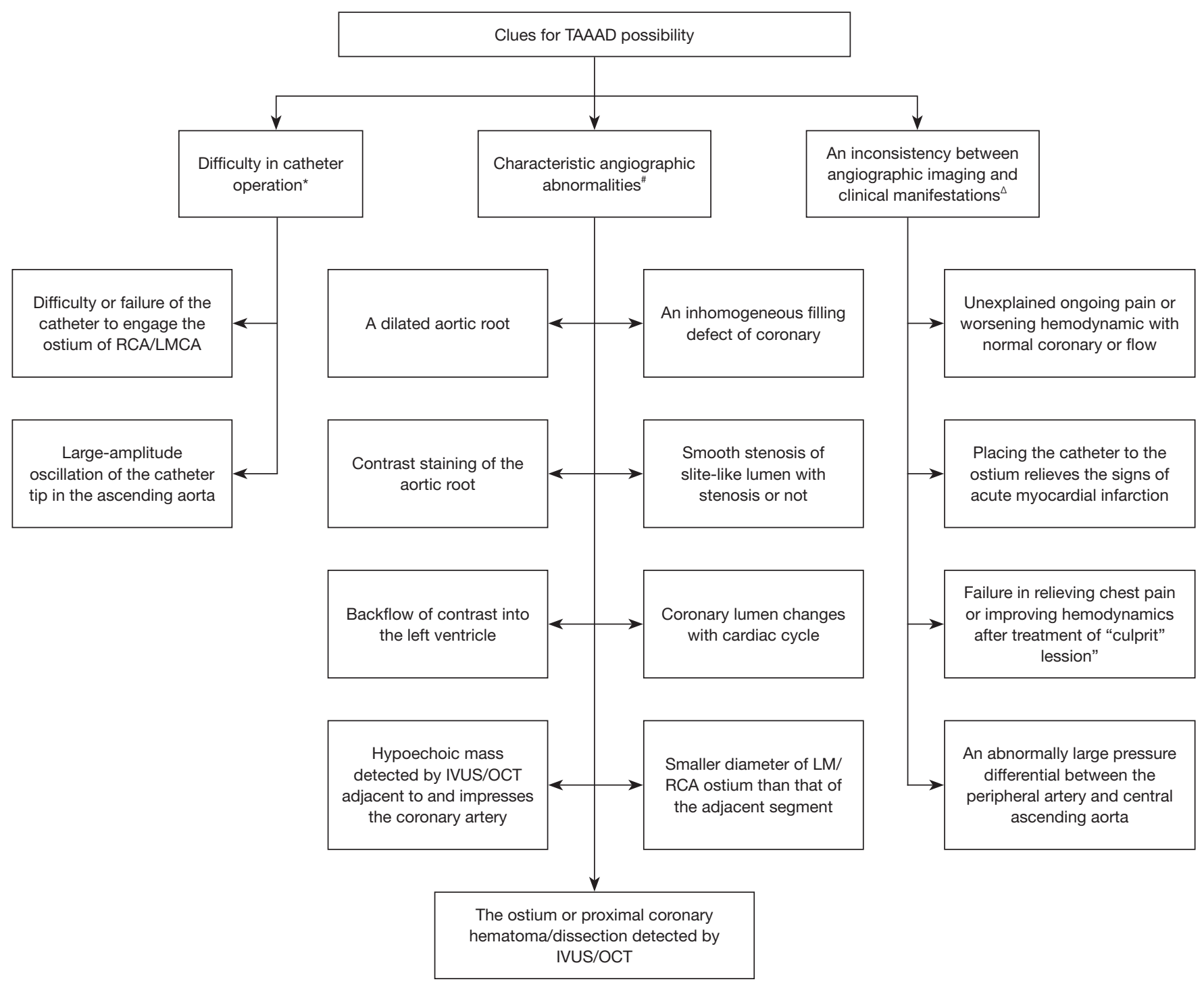

Figure 3 Remedial clues for suspected TAAAD during coronary angiography. *, case reports No. of 10, 12, 15, and 17; \#, case reports No. of $6,8,10,12,14,16-25,44,51$, and $101 ; \stackrel{\triangle}{ }$, case reports No. of 22, 48, 56, 64, 65, 67, 73, 77, 86, 87, 99, and 104. Case reports No. can be available in Table S1. TAAAD, type A acute aortic dissection; CAG, coronary angiography; PCI, percutaneous coronary intervention; RCA, right coronary artery; LMCA, left main coronary artery; IVUS, intravascular ultrasound; OCT, optical coherence tomography.

concerning is the fact that more TTE signs of TAAAD, including intimal flap, were detected in patients with dTTE than those immediately on admission. A possible explanation for this may be that clues for TAAAD available during CAG (summarized in Figure 3) could remind sonographers to look more closely for signs of TAAAD. Therefore, it may be advisable to introduce eTTE into the STEMI process, especially in cases with a high risk of TAAAD, including those with shock or ADRS of 2-3. While this may result in concerns over the delay in coronary perfusion, further shortening door-to-balloon times within 90 minutes bring no significant overall change in mortality (23), and as bedside eTTE can provide red flags warranting emergency aortic imaging just within minutes (10), this might not necessarily delay reperfusion time. Further prospective studies are required to explore whether the total ischemic time is prolonged and the STEMI prognosis is affected by eTTE or whether more TAAAD is identified 
and the prognosis improves.

\section{TTE timing and in-bospital mortality of TAAAD}

Previous studies have established a link between TTE and mortality among patients hospitalized for five specific cardiovascular diseases (24), but the timing has not been considered. In the present study, patients undergoing dTTE had a higher risk of developing in-hospital mortality than eTTE patients in a subgroup of both (I) patients with positive HRE and (II) patients receiving surgery. Several hypotheses have been forwarded to account for this increase in mortality. The first hypothesis suggests dTTE would increase delays to diagnosis, which would worsen outcomes (25), and many patients who experienced delays to diagnosis also experienced delays to surgical treatment of $\mathrm{AD}$ (26). As the preferred initial imaging modality in IRAD, CT is associated with longer surgery delays regardless of the transfer. An aortogram may be performed as part of an evaluation for ACS or in patients undergoing CAG before surgery, which also slows the surgery path. Dissection was more rapidly diagnosed when TTE formed part of the diagnostic workup (17). The imaging study's results showed that very critical patients who have a bedside TTE confirming a diagnosis of proximal AD are frequently sent directly to the operating room. Consistent with the above background, the association between dTTE and in-hospital death was significant only among patients presenting with a positive HRE and surgical therapy, not among those presenting with negative HRE and no surgical treatment. This suggests the benefits of eTTE in improving the prognosis might come from guiding early diagnosis and surgical initiation in high-risk patients.

A second hypothesis suggests the increased use of antithrombotic therapy observed in dTTE cases may increase the risk of complications such as shock and tamponade, as well as perioperative bleeding. The use of preoperative antithrombotic therapy could increase the risk of intraoperative bleeding, thus delay surgery. Moreover, aiming to decrease wall stress and limit the extension of dissection using initial medical therapy is also vital to reduce the risk of developing end-organ damage and rupture (27). Thus, information gained by eTTE to avoid contraindications to management can also optimize the medical therapy related to $\mathrm{AD}$. It is vital to reduce early risk and delay surgery to allow patients to transfer to expert aortic surgery centers. More cases in this study who underwent dTTE received antithrombotic therapy, which may indicate a lack of timely optimal medical management and might be one of the causes for higher in-hospital mortality. However, it is impossible to assert this, given the small sample size and incomplete relevant data.

Thirdly, a focused TTE on the aortic valve complex and distinct aorta segments along with a glimpse into left heart structure and function may provide essential information needed in both anesthetic and surgical protocols for clinical decision-making (28). TTE is an excellent tool to quickly detect the potentially lethal complications of TAAAD, such as aortic regurgitation, pericardial effusion, cardiac tamponade, and wall motion abnormalities. Preoperative TTE findings provided crucial diagnostic information and prognostic value and were useful for improving the management strategy. Pericardial effusion, tamponade, periaortic hematoma, and false patent lumen were more frequent in non-survivors (29). As the least expensive and lowest-risk cardiac imaging modality available, eTTE is a first-tier diagnostic tool that routinely leads to the earlier initiation of various therapeutic interventions such as heart failure regimens, use of implantable devices, surgery, and revascularization, all of which have been shown to improve mortality rates in the appropriate clinical setting.

\section{Limitations}

Our study has some limitations. First, the sample size was small, although the association between dTTE and in-hospital mortality in patients receiving surgery was highly significant. Secondly, the data could be influenced by selection and ascertainment bias. However, as a rare condition of STEMI complicating TAAAD, the most complicated cases were likely reported, but the patients that have been successfully managed will also be useful experiences to be shared, which reduces selection bias to some extent. Thirdly, detailed data on the use of different surgical techniques and medical management, which may have influenced in-hospital mortality, were not included in this study as our study focused on TTE timing. Finally, our study results should be considered hypothesis-generating because of the study's observational nature.

\section{Conclusions}

The delayed performance of TTE was associated with an increase in the in-hospital mortality in STEMI, complicating TAAAD patients with surgery management based on previously published case reports. This detriment's mechanism remains to be explored but may be related 
to the delayed diagnosis and surgery, increased use of antithrombotic therapy, and inadequate medical management as indicated and guided by TTE results. As the incidence of STEMI complicating TAAAD is a rare, randomized controlled trial (RCT)-based data are lacking, and no RCT will likely be performed to provide evidence in the future. The real-world data application provides a way to assess management's clinical effectiveness, such as TTE timing. Our findings should not be taken as the final and definitive word concerning the value of TTE timing in the management of TAAAD associated STEMI. As a reviewed analysis of data from previously published case reports, the potential issues of residual confounding by variables not captured require additional investigation.

\section{Acknowledgments}

Funding: This work was supported by the National Natural Science Foundation of China (NSFC, No. 81803759 and No. 82000312), Shanghai Sailing Program (No. 20YF1439800), and the Clinical Research Innovation Plan of Shanghai General Hospital (No. 16411953100, and CTCCR-2019C06).

\section{Footnote}

Reporting Checklist: The authors have completed the STROBE reporting checklist. Available at http://dx.doi. org/10.21037/jtd-20-3470

Conflicts of Interest: All authors have completed the ICMJE uniform disclosure form (available at http://dx.doi. org/10.21037/jtd-20-3470). The authors have no conflicts of interest to declare.

Ethical Statement: The authors are accountable for all aspects of the work in ensuring that questions related to the accuracy or integrity of any part of the work are appropriately investigated and resolved. The study was conducted in accordance with the Declaration of Helsinki (as revised in 2013). The study was approved by the ethics committee of Shanghai General Hospital affiliated to Shanghai Jiaotong University. (NO.: [2018] 24). Informed consent was not required as the data relating to included patients were from previously published case reports.

Open Access Statement: This is an Open Access article distributed in accordance with the Creative Commons
Attribution-NonCommercial-NoDerivs 4.0 International License (CC BY-NC-ND 4.0), which permits the noncommercial replication and distribution of the article with the strict proviso that no changes or edits are made and the original work is properly cited (including links to both the formal publication through the relevant DOI and the license). See: https://creativecommons.org/licenses/by-nc-nd/4.0/.

\section{References}

1. Berretta P, Trimarchi S, Patel HJ, et al. Malperfusion syndromes in type A aortic dissection: what we have learned from IRAD. J Vis Surg 2018;4:65.

2. Czerny M, Schoenhoff F, Etz C, et al. The Impact of Preoperative Malperfusion on Outcome in Acute Type A Aortic Dissection: Results from the GERAADA Registry. J Am Coll Cardiol 2015;65:2628-35.

3. Neri E, Toscano T, Papalia U, et al. Proximal aortic dissection with coronary malperfusion: presentation, management, and outcome. J Thorac Cardiovasc Surg 2001;121:552-60.

4. Imoto K, Uchida K, Karube N, et al. Risk analysis and improvement of strategies in patients who have acute type A aortic dissection with coronary artery dissection. Eur J Cardiothorac Surg 2013;44:419-24; discussion 424-5.

5. Immer FF, Grobéty V, Lauten A, et al. Does malperfusion syndrome affect early and mid-term outcome in patients suffering from acute type A aortic dissection? Interact Cardiovasc Thorac Surg 2006;5:187-90.

6. Hagan PG, Nienaber CA, Isselbacher EM, et al. The International Registry of Acute Aortic Dissection (IRAD): new insights into an old disease. JAMA 2000;283:897-903.

7. Cavender MA, Milford-Beland S, Roe MT, et al. Prevalence, predictors, and in-hospital outcomes of noninfarct artery intervention during primary percutaneous coronary intervention for ST-segment elevation myocardial infarction (from the National Cardiovascular Data Registry). Am J Cardiol 2009;104:507-13.

8. Hannan EL, Samadashvili Z, Walford G, et al. Culprit vessel percutaneous coronary intervention versus multivessel and staged percutaneous coronary intervention for ST-segment elevation myocardial infarction patients with multivessel disease. JACC Cardiovasc Interv 2010;3:22-31.

9. Politi L, Sgura F, Rossi R, et al. A randomised trial of target-vessel versus multi-vessel revascularisation in STelevation myocardial infarction: major adverse cardiac events during long-term follow-up. Heart 2010;96:662-7. 
10. Nazerian P, Mueller C, Vanni S, et al. Integration of transthoracic focused cardiac ultrasound in the diagnostic algorithm for suspected acute aortic syndromes. Eur Heart J 2019;40:1952-60.

11. Pack QR, Priya A, Lagu T, et al. Association Between Inpatient Echocardiography Use and Outcomes in Adult Patients with Acute Myocardial Infarction. JAMA Intern Med 2019;179:1176-85.

12. Ibanez B, James S, Agewall S, et al. 2017 ESC Guidelines for the management of acute myocardial infarction in patients presenting with ST-segment elevation: The Task Force for the management of acute myocardial infarction in patients presenting with ST-segment elevation of the European Society of Cardiology (ESC). Eur Heart J 2018;39:119-77.

13. Yan AT, Yan RT, Kennelly BM, et al. Relationship of ST elevation in lead aVR with angiographic findings and outcome in non-ST elevation acute coronary syndromes. Am Heart J 2007;154:71-8.

14. Matulevicius SA, Rohatgi A, Das SR, et al. Appropriate use and clinical impact of transthoracic echocardiography. JAMA Intern Med 2013;173:1600-7.

15. Pape LA, Awais M, Woznicki EM, et al. Presentation, Diagnosis, and Outcomes of Acute Aortic Dissection: 17-Year Trends from the International Registry of Acute Aortic Dissection. J Am Coll Cardiol 2015;66:350-8.

16. Evangelista A, Isselbacher EM, Bossone E, et al. Insights from the International Registry of Acute Aortic Dissection: A 20-Year Experience of Collaborative Clinical Research. Circulation 2018;137:1846-60.

17. Bossone E, Pyeritz RE, Braverman AC, et al. shock complicating type A acute aortic dissection: Clinical correlates, management, and outcomes. Am Heart J 2016;176:93-9.

18. Rapezzi C, Longhi S, Graziosi M, et al. Risk factors for diagnostic delay in acute aortic dissection. Am J Cardiol 2008;102:1399-406.

19. Hansen MS, Nogareda GJ, Hutchison SJ. Frequency of

Cite this article as: Liu B, Cai LD, Wang Y. Association between delayed transthoracic echocardiography and inhospital mortality in type A acute aortic dissection-associated ST-segment elevated myocardial infarction. J Thorac Dis 2021;13(5):2923-2932. doi: 10.21037/jtd-20-3470 and inappropriate treatment of misdiagnosis of acute aortic dissection. Am J Cardiol 2007;99:852-6.

20. Erbel R, Aboyans V, Boileau C, et al. 2014 ESC Guidelines on the diagnosis and treatment of aortic diseases:

Document covering acute and chronic aortic diseases of the thoracic and abdominal aorta of the adult. The Task Force for the Diagnosis and Treatment of Aortic Diseases of the European Society of Cardiology (ESC). Eur Heart J 2014;35:2873-926.

21. Iliceto S, Antonelli G, Biasco G, et al. Two-dimensional echocardiographic evaluation of aneurysms of the descending thoracic aorta. Circulation 1982;66:1045-9.

22. Victor MF, Mintz GS, Kotler MN, et al. Two dimensional echocardiographic diagnosis of aortic dissection. Am J Cardiol 1981;48:1155-9.

23. Menees DS, Peterson ED, Wang Y, et al. Door-to-balloon time and mortality among patients undergoing primary PCI. N Engl J Med 2013;369:901-9.

24. Papolos A, Narula J, Bavishi C, US Hospital Use of Echocardiography: Insights From the Nationwide Inpatient Sample. J Am Coll Cardiol 2016;67:502-11.

25. Bekkers JA, Raap GB, Takkenberg JJ et al. Acute type A aortic dissection: long-term results and reoperations. Eur J Cardiothorac Surg 2013;43:389-96.

26. Harris KM, Strauss CE, Eagle KA, et al. Correlates of delayed recognition and treatment of acute type A aortic dissection: the International Registry of Acute Aortic Dissection (IRAD). Circulation 2011;124:1911-8.

27. Aggarwal B, Raymond CE. Therapeutic goals in patients with acute aortic dissection: management before surgery. JACC 2015;65:1599-600.

28. Via G, Hussain A, Wells M, et al. International evidencebased recommendations for focused cardiac ultrasound. J Am Soc Echocardiogr 2014;27:683.e1-683.e33.

29. Bossone E, Evangelista A, Isselbacher E, et al. Prognostic role of transesophageal echocardiography in acute type A aortic dissection. Am Heart J 2007;153:1013-20. 
Table S1 The list of case reports

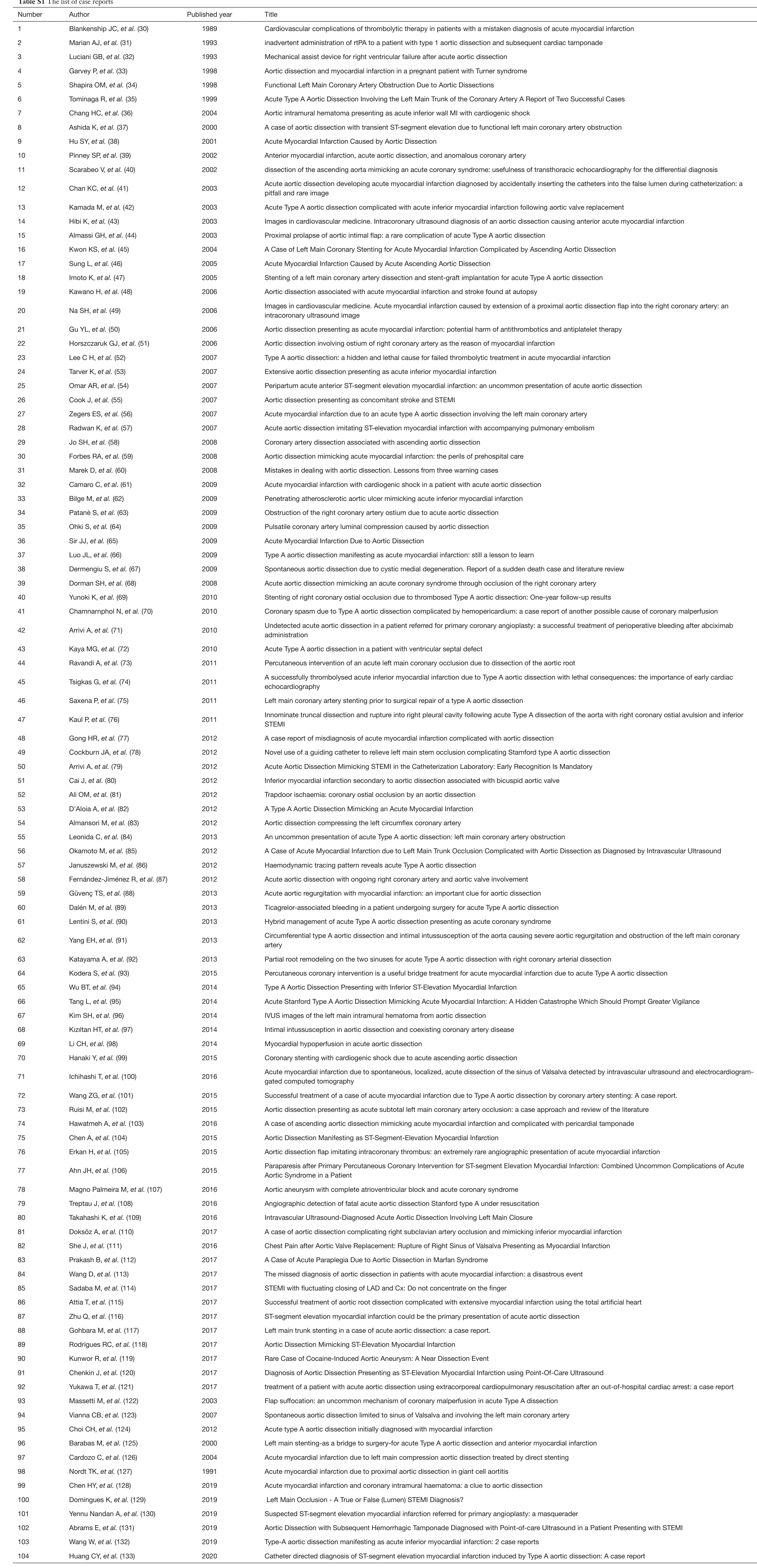


Table S2 Baseline variables associated with in-hospital mortality

\begin{tabular}{|c|c|c|c|}
\hline Variables & Survive $(n=75)$ & Death $(n=34)$ & $P$ value \\
\hline Male, n (\%) & $53(70.67)$ & $22(64.71)$ & 0.534 \\
\hline $\mathrm{SBP}$, mean $\pm \mathrm{SD}, \mathrm{mmHg}$ & $98.15 \pm 27.29$ & $105.57 \pm 46.71$ & 0.410 \\
\hline $\mathrm{DBP}$, mean $\pm \mathrm{SD}, \mathrm{mmHg}$ & $57.88 \pm 17.10$ & $64.61 \pm 28.93$ & 0.269 \\
\hline Hypotension/shock, n (\%) & $33(44.00)$ & $17(50.00)$ & 0.560 \\
\hline Chest pain, n (\%) & $74(98.67)$ & $31(91.18)$ & 0.054 \\
\hline Back pain, n (\%) & $10(13.33)$ & $6(17.65)$ & 0.555 \\
\hline Abdominal pain, n (\%) & $1(1.35)$ & $3(8.82)$ & 0.056 \\
\hline HRE, n (\%) & $41(57.75)$ & 25 (78.12) & 0.046 \\
\hline CR, n (\%) & $21(28.00)$ & $14(41.18)$ & 0.172 \\
\hline CAG, n (\%) & $59(78.67)$ & $22(64.71)$ & 0.122 \\
\hline \multicolumn{4}{|l|}{ Type of STEMI, n (\%) } \\
\hline Anterior STEMI & $33(45.83)$ & $16(48.48)$ & 0.800 \\
\hline Inferior STEMI & $39(54.17)$ & $17(51.52)$ & 0.800 \\
\hline Aortogram, n (\%) & 37 (49.33) & $14(41.18)$ & 0.429 \\
\hline IVUS/OCT, n (\%) & $13(17.33)$ & $2(5.88)$ & 0.108 \\
\hline $\mathrm{PCl}, \mathrm{n}(\%)$ & $19(25.33)$ & $6(17.65)$ & 0.377 \\
\hline Surgery, n (\%) & 70 (93.33) & $17(50.00)$ & $<0.001$ \\
\hline
\end{tabular}

SD, standard deviation; TTE, transthoracic echocardiography; SBP, systolic blood pressure; DBP, diastolic blood pressure; HR, heart rate; HRC, high-risk condition; HRP, high-risk pain; HRE, high-risk examination; CR, chest radiograph; CAG, coronary angiography; STEMI, ST-segment elevated myocardial infarction; IVUS, intravascular ultrasound; OCT, optical coherence tomography; CTA, computed tomography angiography; MRI, magnetic resonance imaging; TEE, transesophageal echocardiography; PCI, percutaneous coronary intervention. 


\section{References}

30. Blankenship JC, Almquist AK. Cardiovascular complications of thrombolytic therapy in patients with a mistaken diagnosis of acute myocardial infarction. J Am Coll Cardiol 1989;14:1579-82.

31. Marian AJ, Harris SL, Pickett JD, et al. inadvertent administration of rtPA to a patient with type 1 aortic dissection and subsequent cardiac tamponade. Am J Emerg Med 1993;11:613-5.

32. Luciani GB, Fabbri A, Faggian G, et al. Mechanical assist device for right ventricular failure after acute aortic dissection. Ann Thorac Surg 1993;56:363-6.

33. Garvey P, Elovitz M, Landsberger EJ. Aortic dissection and myocardial infarction in a pregnant patient with Turner syndrome. Obstet Gynecol 1998;91:864.

34. Shapira OM, Davidoff R. Functional Left Main Coronary Artery Obstruction Due to Aortic Dissection. Circulation 1998;98:278-80

35. Tominaga R, Tomita Y, Toshima Y, et al. Acute Type A Aortic Dissection Involving the Left Main Trunk of the Coronary Artery A Report of Two Successful Cases. Jpn Circ J 1999;63:722-24.

36. Chang HC, Yeh KH, Huang HL, et al. Aortic intramural hematoma presenting as acute inferior wall $\mathrm{MI}$ with cardiogenic shock. Am J Emerg Med 2004;22:433-6.

37. Ashida K, Arakawa K, Yamagishi T, et al. A case of aortic dissection with transient ST-segment elevation due to functional left main coronary artery obstruction. Jpn Circ J 2000;64:130-4.

38. Hu SY, Wang CC, Wei HJ, et al. Acute Myocardial Infarction Caused by Aortic Dissection. Chinese Medical Journal (Taipei) 2001;64:535-9.

39. Pinney SP, Wasserman HS. Anterior myocardial infarction, acute aortic dissection, and anomalous coronary artery. J Interv Cardiol 2002;15:293-6.

40. Scarabeo V, Di Marco A, Pantaleoni A, et al. dissection of the ascending aorta mimicking an acute coronary syndrome: usefulness of transthoracic echocardiography for the differential diagnosis. Ital Heart J 2002;3:490-4.

41. Chan KC, Wu DJ, Ueng KC, et al. Acute aortic dissection developing acute myocardial infarction diagnosed by accidentally inserting the catheters into the false lumen during catheterization: a pitfall and rare image. Jpn Heart J 2003;44:583-5.

42. Kamada M, Ohsaka K, Nagamine S, et al. Acute Type A aortic dissection complicated with acute inferior myocardial infarction following aortic valve replacement.
Jpn J Thorac Cardiovasc Surg 2003;51:552-6.

43. Hibi K, Kimura K, Nakagawa T, et al. Images in cardiovascular medicine. Intracoronary ultrasound diagnosis of an aortic dissection causing anterior acute myocardial infarction. Circulation 2003;108:e145-6.

44. Almassi GH. Proximal prolapse of aortic intimal flap: a rare complication of acute Type A aortic dissection. J Thorac Cardiovasc Surg 2003;125:1546-8.

45. Kwon KS, Lee HS, Shin JK, et al. A Case of Left Main Coronary Stenting for Acute Myocardial Infarction Complicated by Ascending Aortic Dissection. Korean Circulation J 2004;34:1210-5.

46. Sung L, Kuo C, Hu P, et al. Acute Myocardial Infarction Caused by Acute Ascending Aortic Dissection. Acta Cardiol Sin 2005;21:105-10.

47. Imoto K, Uchida K, Suzuki S, et al. Stenting of a left main coronary artery dissection and stent-graft implantation for acute Type A aortic dissection. J Endovasc Ther 2005;12:258-61.

48. Kawano H, Tomichi Y, Fukae S, et al. Aortic dissection associated with acute myocardial infarction and stroke found at autopsy. Intern Med 2006;45:957-62.

49. Na SH, Youn TJ, Cho YS, et al. Images in cardiovascular medicine. Acute myocardial infarction caused by extension of a proximal aortic dissection flap into the right coronary artery: an intracoronary ultrasound image. Circulation 2006;113:e669-71.

50. Gu YL, van den Heuvel AF, Erasmus ME, et al. Aortic dissection presenting as acute myocardial infarction: potential harm of antithrombin and antiplatelet therapy. Neth Heart J 2006;14:147-9.

51. Horszczaruk GJ, Roik MF, Kochman J, et al. Aortic dissection involving ostium of right coronary artery as the reason of myocardial infarction. Eur Heart J 2006;27:518.

52. Lee CH, Lim J. Type A aortic dissection: a hidden and lethal cause for failed thrombolytic treatment in acute myocardial infarction. Heart 2007;93:825

53. Tarver K, Kindler H, Lythall D. Extensive aortic dissection presenting as acute inferior myocardial infarction. Heart 2007;93:1225.

54. Omar AR, Goh WP, Lim YT. Peripartum acute anterior ST-segment elevation myocardial infarction: an uncommon presentation of acute aortic dissection. Ann Acad Med Singapore 2007;36:854-6.

55. Cook J, Aeschlimann S, Fuh A, et al. Aortic dissection presenting as concomitant stroke and STEMI. J Hum Hypertens 2007;21:818-21.

56. Zegers ES, Gehlmann HR, Verheugt FWA. Acute 
myocardial infarction due to an acute type A aortic dissection involving the left main coronary artery. Neth Heart J 2007;15:263-4.

57. Radwan K, Peszek-Przybyła E, Gruszka A, et al. Acute aortic dissection imitating ST-elevation myocardial infarction with accompanying pulmonary embolism. Cardiol J 2007;14:595-6.

58. Jo SH, Kang HJ, Koo BK. Coronary artery dissection associated with ascending aortic dissection. Can J Cardiol 2008;24:643.

59. Forbes RA, Balderston G. Aortic dissection mimicking acute myocardial infarction: the perils of prehospital care. Prehosp Emerg Care 2008;12:503-5.

60. Marek D, Nemec P, Herman M, et al. Mistakes in dealing with aortic dissection. Lessons from three warning cases.

Biomed Pap Med Fac Univ Palacky Olomouc Czech Repub 2008;152:283-7.

61. Camaro C, Wouters NT, Gin MT, et al. Acute myocardial infarction with cardiogenic shock in a patient with acute aortic dissection. Am J Emerg Med 2009;27:899.e3-6.

62. Bilge M, Kurt M, Senkaya EB, et al. Penetrating atherosclerotic aortic ulcer mimicking acute inferior myocardial infarction. Echocardiography 2009;26:1084-6.

63. Patanè S, Marte F, Lentini S, et al. Obstruction of the right coronary artery ostium due to acute aortic dissection. Int J Cardiol 2009;133:135-7.

64. Ohki S, Moriyama Y, Sata N, et al. Pulsatile coronary artery luminal compression caused by aortic dissection. Ann Thorac Surg 2009;87:1298.

65. Sir JJ, Kim YI, Cho WH, et al. Acute Myocardial Infarction Due to Aortic Dissection. Intern Med 2009;48:173.

66. Luo JL, Wu CK, Lin YH, et al. Type A aortic dissection manifesting as acute myocardial infarction: still a lesson to learn. Acta Cardiol 2009;64:499-504.

67. Dermengiu S, Ceausu M, Hostiuc S, et al. Spontaneous aortic dissection due to cystic medial degeneration. Report of a sudden death case and literature review. Rom J Leg Med 2009;2:89-96.

68. Dorman SH, Barry J. Acute aortic dissection mimicking an acute coronary syndrome through occlusion of the right coronary artery. Emerg Med J 2008;25:462-3.

69. Yunoki K, Naruko T, Itoh A, et al. Stenting of right coronary ostial occlusion due to thrombosed Type A aortic dissection: One-year follow-up results. J Cardiol Cases 2010;1:e166-70.

70. Chamnarnphol N, Cheewatanakornkul S, Wisaratapong T. Coronary spasm due to Type A aortic dissection complicated by hemopericardium: a case report of another possible cause of coronary malperfusion. Intern Med 2010;49:829-31.

71. Arrivi A, Tanzilli G, Tritapepe L, et al. Undetected acute aortic dissection in a patient referred for primary coronary angioplasty: a successful treatment of perioperative bleeding after abciximab administration. BMJ Case Rep 2010;2010:bcr1020103382.

72. Kaya MG, Mavili E, Dogdu O, et al. Acute Type A aortic dissection in a patient with ventricular septal defect. Cardiovasc Revasc Med 2010;11:186-8.

73. Ravandi A, Penny WF. Percutaneous intervention of an acute left main coronary occlusion due to dissection of the aortic root. JACC Cardiovasc Interv 2011;4:713-5.

74. Tsigkas G, Kasimis G, Theodoropoulos K, et al. A successfully thrombolysed acute inferior myocardial infarction due to Type A aortic dissection with lethal consequences: the importance of early cardiac echocardiography. J Cardiothorac Surg 2011;6:101.

75. Saxena P, Boyle A, Shetty S, et al. Left main coronary artery stenting prior to surgical repair of a type A aortic dissection. J Card Surg 2011;26:634-5.

76. Kaul P, George R, Paniagua R, et al. Innominate truncal dissection and rupture into right pleural cavity following acute Type A dissection of the aorta with right coronary ostial avulsion and inferior STEMI. Perfusion 2011;26:435-40.

77. Gong HR, Li XP, Ye HJ. A case report of misdiagnosis of acute myocardial infarction complicated with aortic dissection. Zhonghua Xin Xue Guan Bing Za Zhi 2012;40:792-3.

78. Cockburn JA, Munir SM, Prendergast BD. Novel use of a guiding catheter to relieve left main stem occlusion complicating Stamford type A aortic dissection. J Cardiol Cases 2012;6:e23-5.

79. Arrivi A, Tanzilli G, Puddu PE, et al. Acute Aortic Dissection Mimicking STEMI in the Catheterization Laboratory: Early Recognition Is Mandatory. Case Rep Cardiol 2012;2012:367542.

80. Cai J, Cao Y, Yuan H, et al. Inferior myocardial infarction secondary to aortic dissection associated with bicuspid aortic valve. J Cardiovasc Dis Res 2012;3:138-42.

81. Ali OM, White B. Trapdoor ischaemia: coronary ostial occlusion by an aortic dissection. BMJ Case Rep 2012;2012:bcr2012006875.

82. D'Aloia A, Vizzardi E, Bugatti S, et al. A Type A Aortic Dissection Mimicking an Acute Myocardial Infarction. Cardiol Res 2012;3:94-96. 
83. Almansori M, Tymchak W. Aortic dissection compressing the left circumflex coronary artery. Can J Cardiol 2012;28:760.e5-6.

84. Leonida C. An uncommon presentation of acute Type A aortic dissection: left main coronary artery obstruction. J Cardiovasc Med (Hagerstown) 2013;14:69-70.

85. Okamoto M, Amano T, Matsuoka S, et al. A Case of Acute Myocardial Infarction due to Left Main Trunk Occlusion Complicated with Aortic Dissection as Diagnosed by Intravascular Ultrasound. Cardiol Res 2012;3:232-5.

86. Jaguszewski M, Widmer N, Ghadri JR, et al. Haemodynamic tracing pattern reveals acute type A aortic dissection. Acute Card Care 2012;14:94-5.

87. Fernández-Jiménez R, Vivas D, de Agustín JA, et al. Acute aortic dissection with ongoing right coronary artery and aortic valve involvement. Int J Cardiol 2012;161:e34-6.

88. Güvenç TS, Erer HB, Çetin R, et al. Acute aortic regurgitation with myocardial infarction: an important clue for aortic dissection. J Emerg Med 2013;44:e5-8.

89. Dalén M, Ivert T, Lindvall G, et al. Ticagrelorassociated bleeding in a patient undergoing surgery for acute Type A aortic dissection. J Cardiothorac Vasc Anesth 2013;27:e55-7.

90. Lentini S, Specchia L, Cricco A, et al. Hybrid management of acute Type A aortic dissection presenting as acute coronary syndrome. Int J Cardiol 2013;167:e85-7.

91. Yang EH, Kwon MH, Mahajan A, et al. Circumferential type A aortic dissection and intimal intussusception of the aorta causing severe aortic regurgitation and obstruction of the left main coronary artery. Echocardiography 2013;30:E81-4.

92. Katayama A, Uchida N, Sutoh M, et al. Partial root remodeling on the two sinuses for acute type A aortic dissection with right coronary arterial dissection. Ann Vasc Dis 2013;6:666-9.

93. Kodera S, Ikeda M, Sato K, et al. Percutaneous coronary intervention is a useful bridge treatment for acute myocardial infarction due to acute Type A aortic dissection. Cardiovasc Interv Ther 2015;30:61-7.

94. Wu BT, Li CY, Chen YT. Type A Aortic Dissection Presenting with Inferior ST-Elevation Myocardial Infarction. Acta Cardiol Sin 2014;30:248-52.

95. Tang L, Hu XQ, Zhou SH. Acute Stanford Type A Aortic Dissection Mimicking Acute Myocardial Infarction: A Hidden Catastrophe Which Should Prompt Greater Vigilance. Acta Cardiol Sin 2014;30:493-6.

96. Kim SH, Kim KH, Lim SW, et al. IVUS images of the left main intramural hematoma from aortic dissection. Int $\mathrm{J}$
Cardiol 2014;173:e27-30.

97. Kızıltan HT, Tıraş M, Idem A, et al. Intimal intussusception in aortic dissection and coexisting coronary artery disease. Ann Thorac Surg 2014;97:698-700.

98. Li CH, Leta R, Pons-Lladó G. Myocardial hypoperfusion in acute aortic dissection. Rev Esp Cardiol (Engl Ed) 2014;67:323.

99. Hanaki Y, Yumoto K, I S, Aoki H, et al. Coronary stenting with cardiogenic shock due to acute ascending aortic dissection. World J Cardiol 2015;7:104-10.

100. Ichihashi T, Ito T, Murai S, et al. Acute myocardial infarction due to spontaneous, localized, acute dissection of the sinus of Valsalva detected by intravascular ultrasound and electrocardiogram-gated computed tomography. Heart Vessels 2016;31:1570-3.

101. Wang ZG, Zhao W, Shen BT, et al. Successful treatment of a case of acute myocardial infarction due to Type A aortic dissection by coronary artery stenting: A case report. Exp Ther Med 2015;10:759-62.

102. Ruisi M, Fallahi A, Lala M, et al. Aortic dissection presenting as acute subtotal left main coronary artery occlusion: a case approach and review of the literature. J Clin Med Res 2015;7:356-60.

103. Hawatmeh A, Abu Arqoub A, Isbitan A, et al. A case of ascending aortic dissection mimicking acute myocardial infarction and complicated with pericardial tamponade. Cardiovasc Diagn Ther 2016;6:166-71.

104. Chen A, Ren X. Aortic Dissection Manifesting as STSegment-Elevation Myocardial Infarction. Circulation 2015;131:e503-4.

105.Erkan H, Çirakoğlu ÖF, Erkan M, et al. Aortic dissection flap imitating intracoronary thrombus: an extremely rare angiographic presentation of acute myocardial infarction. J Interv Cardiol 2015;28:117-8.

106.Ahn JH, Park JR, Koh JS, et al. Paraparesis after Primary Percutaneous Coronary Intervention for ST-segment Elevation Myocardial Infarction: Combined Uncommon Complications of Acute Aortic Syndrome in a Patient. Intern Med 2015;54:2191-5.

107. Magno Palmeira M, Umemura Ribeiro HY, Garcia Lira $\mathrm{Y}$, et al. Aortic aneurysm with complete atrioventricular block and acute coronary syndrome. BMC Res Notes 2016;9:257.

108. Treptau J, Ebnet J, Akin M, et al. Angiographic detection of fatal acute aortic dissection Stanford type A under resuscitation. Cardiol J 2016;23:620-2.

109. Takahashi K, Inaba S, Kikuchi K, et al. Intravascular Ultrasound-Diagnosed Acute Aortic Dissection 
Involving Left Main Closure. JACC Cardiovasc Interv 2016;9:1631-2.

110.Doksöz A, Öztürk MT, Salha W, et al. A case of aortic dissection complicating right subclavian artery occlusion and mimicking inferior myocardial infarction. J Emerg Med Case Rep 2017;8:40-2.

111. She J, Hu Z, Deng Y, et al. Chest Pain after Aortic Valve Replacement: Rupture of Right Sinus of Valsalva Presenting as Myocardial Infarction. Cardiology 2016;134:22-5.

112.Prakash B, Pai RK, Chaitra V, et al. A Case of Acute Paraplegia Due to Aortic Dissection in Marfan Syndrome. J Neurosci Rural Pract 2017;8:316-9.

113. Wang D, Zhang LL, Wang ZY, et al. The missed diagnosis of aortic dissection in patients with acute myocardial infarction: a disastrous event. J Thorac Dis 2017;9:E636-9.

114. Sadaba M, Subinas A, Rumoroso JR. STEMI with fluctuating closing of LAD and Cx: Do not concentrate on the finger. Cardiovasc Revasc Med 2017;18:S35-9.

115.Attia T, Robich M, Lincoff AM, et al. Successful treatment of aortic root dissection complicated with extensive myocardial infarction using the total artificial heart. J Surg Case Rep 2017;2017:rjx123.

116.Zhu Q, Tai S, Tang L, et al. ST-segment elevation myocardial infarction could be the primary presentation of acute aortic dissection. American Journal of Emergency Medicine 2017;11:1713.

117.Gohbara M, Endo T, Kimura K, et al. Left main trunk stenting in a case of acute aortic dissection: a case report. Clin Case Rep 2017;5:1649-53.

118. Rodrigues RC, Santos N, Pereira D. Aortic Dissection Mimicking ST-Elevation Myocardial Infarction. Acta Med Port 2017;30:80.

119. Kunwor R, Canelas A. Rare Case of Cocaine-Induced Aortic Aneurysm: A Near Dissection Event. Case Rep Cardiol 2017;2017:1785410.

120. Chenkin J. Diagnosis of Aortic Dissection Presenting as ST-Elevation Myocardial Infarction using Point-Of-Care Ultrasound. J Emerg Med 2017;53:880-4.

121. Yukawa T, Sugiyama K, Miyazaki K, et al. treatment of a patient with acute aortic dissection using extracorporeal cardiopulmonary resuscitation after an out-ofhospital cardiac arrest: a case report. Acute Med Surg 2017;5:189-93.
122.Massetti M, Neri E, Babatasi G, et al. Flap suffocation: an uncommon mechanism of coronary malperfusion in acute Type A dissection. J Thorac Cardiovasc Surg 2003;125:1548-50.

123. Vianna CB, Puig LB, Vieira ML, et al. Spontaneous aortic dissection limited to sinus of Valsalva and involving the left main coronary artery. Int J Cardiovasc Imaging 2007;23:455-8

124. Choi CH, Park CH, Park KY, et al. Acute type A aortic dissection initially diagnosed with myocardial infarction. Korean J Thorac Cardiovasc Surg 2012;45:424-5.

125. Barabas M, Gosselin G, Crépeau J, et al. Left main stenting-as a bridge to surgery-for acute Type A aortic dissection and anterior myocardial infarction. Catheter Cardiovasc Interv 2000;51:74-7.

126. Cardozo C, Riadh R, Mazen M. Acute myocardial infarction due to left main compression aortic dissection treated by direct stenting. J Invasive Cardiol 2004;16:89-91.

127.Nordt TK, Rauch B, Mattfeldt T, et al. Acute myocardial infarction due to proximal aortic dissection in giant cell aortitis. Am Heart J 1991;122:1151-3.

128. Chen HY, Lu DY, Sung SH. Acute myocardial infarction and coronary intramural haematoma: a clue to aortic dissection. EuroIntervention 2019;14:e1852-3.

129. Domingues K, Duarte JA, Canas da Silva P. Left Main Occlusion - A True or False (Lumen) STEMI Diagnosis? J Emerg Med 2019;56:e27-30.

130. Yennu Nandan A, Singh A, Mukundu Nagesh N, et al. Suspected ST segment elevation myocardial infarction referred for primary angioplasty: a masquerader. BMJ Case Rep 2019;12:bcr-2018-227687.

131.Abrams E, Allen A, Lahham S. Aortic Dissection with Subsequent Hemorrhagic Tamponade Diagnosed with Point-of-care Ultrasound in a Patient Presenting with STEMI. Clin Pract Cases Emerg Med 2019;3:103-6.

132. Wang $\mathrm{W}, \mathrm{Wu} \mathrm{J}$, Zhao X, et al. Type-A aortic dissection manifesting as acute inferior myocardial infarction: 2 case reports. Medicine (Baltimore) 2019;98:e17662.

133. Huang CY, Hung YP, Lin TH, et al. catheter directed diagnosis of ST-segment elevation myocardial infarction induced by Type A aortic dissection: A case report. Medicine (Baltimore) 2020;99:e18796. 